\title{
High-performance size-exclusion chromatography studies on the formation and distribution of polar compounds in camellia seed oil during heating*
}

\author{
Hong-xia FENG ${ }^{1}$, Rokayya SAM ${ }^{1,2}$, Lian-zhou JIANG ${ }^{\dagger 1}$, Yang LI $^{\dagger+1}$, Wen-ming CAO $^{3}$ \\ ( ${ }^{1}$ College of Food Science, Northeast Agricultural University, Harbin 150030, China) \\ ( ${ }^{2}$ Department of Nutrition and Food Science, Taif University, Taif 888, Kingdom of Saudi Arabia) \\ ( ${ }^{3}$ Shanghai Grain Science Research Institute, Shanghai 200333, China) \\ †E-mail: jianglianzhousci@163.com; 18245153561@163.com \\ Received Apr. 17, 2016; Revision accepted Sept. 16, 2016; Crosschecked Oct. 18, 2016
}

\begin{abstract}
Camellia seed oil (CSO) is rich in oleic acid and has a high number of active components, which give the oil high nutritional value and a variety of biological activity. The aim of the present study was to determine the changes in the content and distribution of total polar compounds (TPC) in CSO during heating. TPC were isolated by means of preparative flash chromatography and further analyzed by high-performance size-exclusion chromatography (HPSEC). The TPC content of CSO increased from $4.74 \%$ to $25.29 \%$, showing a significantly lower formation rate as compared to that of extra virgin olive oil (EVOO) and soybean oil (SBO) during heating. Furthermore, heating also resulted in significant differences $(P<0.05)$ in the distribution of TPC among these oils. Though the content of oxidized triacylglycerol dimers, oxidized triacylglycerol oligomers, and oxidized triacylglycerol monomers significantly increased in all these oils, their increased percentages were much less in CSO than those in EVOO, indicating that CSO has a greater ability to resist oxidation. This work may be useful for the food oil industry and consumers in helping to choose the correct oil and to decide on the useful lifetime of the oil.
\end{abstract}

Key words: Camellia seed oil, Polar compounds, High-performance size-exclusion chromatography, Oxidation http://dx.doi.org/10.1631/jzus.B1600173 CLC number: TS221

\section{Introduction}

Camellia oleifera Abel, an ornamental plant widely distributed in China and Western countries (Zeb, 2012), has recently received great attention as a source of edible oil. Camellia seed oil (CSO), obtained from its seeds, is rich in oleic acid and contains many active compounds (Wang X.Q. et al., 2014). It

\footnotetext{
\$Corresponding authors

* Project supported by the National Natural Science Foundation of China (No. 31430067), the Northeast Agricultural University Innovation Foundation for Postgraduate of Heilongjiang Province (No. yjscx14058), and the National High-Tech R \& D Program (863) of China (No. 2013AA102104)

(iD) ORCID: Hong-xia FENG, http://orcid.org/0000-0002-9781-0282

(C) Zhejiang University and Springer-Verlag Berlin Heidelberg 2016
}

is found to have suitable nutritional characteristics and medical values (Salinero et al., 2012; Wang Y.F. et al., 2014), and is sometimes termed as "Oriental olive oil". So far, most studies on CSO have been focused on chemical characterization (Su et al., 2014; Wang X.Q. et al., 2014), especially some active components and antioxidant capacity, the extraction (Li et al., 2013; Lim et al., 2013), refining process (Na, 2008), and adulteration (Hai and Wang, 2006). Few studies have been reported on its formation of degradation compounds during heating. However, heating treatments are an essential process for edible oil.

During heat treatment, vegetable oils undergo hydrolysis, oxidation, and thermal decomposition, 
resulting in the formation of total polar compounds (TPC), which are of larger molecular weight and higher polarity than general triacylglycerols (Guillén and Uriarte, 2013). These compounds can be separated from the oil and the levels of their contents are considered to be the most reliable index of the quality of the used oils (Farhoosh and Tavassoli-Kafrani, 2010), and is the basis of the international regulations limiting the use of degraded oils for human consumption (Correia et al., 2015). Further analysis via high-performance size-exclusion chromatography (HPSEC) can divide TPC into various classes of substances, namely, oxidized triacylglycerol dimers (TGD), oxidized triacylglycerol oligomers (TGO), oxidized triacylglycerol monomers (ox-TGM), diacylglycerols (DAG), and free fatty acids (FFA) to assess the level of oxidative and hydrolytic degradation of the oils. Even when of similar overall content level, TPC will vary significantly in the distribution of type (Farhoosh and Tavassoli-Kafrani, 2010). Moreover, these polar components differed not only in molecular weight or pro-oxidant property (Paradiso et al., 2010; Gomes et al., 2011) but also in toxicological characteristics (Wenci, 2014), and thus it is important to know the contribution of each of them to the total alteration.

It is noteworthy that the hydrolysis involves breakage of the ester bond with the formation of FFA, DAG, glycerols, and monoglycerides, while the oxidation and thermal decomposition take place in the unsaturated acyl groups of the triacylglycerols (Dobarganes et al., 1988). It is difficult to avoid the formation of TPC in oils during heating. However, their formation rates are significantly influenced by the fatty acid composition of the oil (Martín-Polvillo et al., 2004) and the amount and type of natural antioxidants in the oil (Farhoosh and Tavassoli-Kafrani, 2010). Therefore, it is possible to select the oil with strong antioxidant properties to reduce the formation rate of TPC. As an edible oil, CSO has a high content of total phenolics (65.9 mg gallic acid equivalents per kilogram of oil (mg GAE/kg)), which give it good performance during heating.

The aim of this paper is to study the formation of TPC in CSO during heating. Changes in the distribution of TPC as well as comparison with common edible oils, such as extra virgin olive oil (EVOO), soybean oil (SBO), and palm oil (PO) are also reported.

\section{Materials and methods}

\subsection{Materials}

The oils for this study, CSO, EVOO, SBO, and $\mathrm{PO}$, were acquired from a local supermarket. The tetrahydrofuran (THF, Merk Corporation, USA) used for the HPSEC analysis was of chromatography grade, and was purchased from Tedia Company (Fairfield, USA). Glass plates $(20 \mathrm{~cm} \times 20 \mathrm{~cm})$ for thin-layer chromatography were coated with silica gel (without fluorescence indicator) at $0.25 \mathrm{~mm}$ layer thickness. The developing solvent was a mixture of petroleum ether (boiling range from 30 to $60{ }^{\circ} \mathrm{C}$ ), diethyl ether, and acetic acid (70/30/2, v/v/v). Phosphomolybdic acid solution $(100 \mathrm{~g} / \mathrm{L})$ in ethanol was applied as spray. All other chemical solvents used were of analytical grade, and were purchased from Shengda Chemical Reagent Co., Lid. (Heilongjiang, China).

\subsection{Thermal oxidation experiment}

Thermal oxidation was carried out under strictly controlled conditions using an electric heater, equipped with an intelligent digital display and a magnetic stirrer (ZNCL-T/100 ml/150, Zhengzhou, China). The samples were treated under identical conditions. Equivalent samples of oils $((100 \pm 0.01) \mathrm{g})$ were weighed accurately into round-bottomed flasks of the same volume $(100 \mathrm{ml})$, and inserted in the electric heater previously heated to $(180 \pm 1){ }^{\circ} \mathrm{C}$. Throughout the heating process no oil was replenished. Oil samples were periodically (every $2 \mathrm{~h}$ ) taken in duplicate, and refrigerated at $-40{ }^{\circ} \mathrm{C}$ until studied in order to avoid the continuation of the degradation process.

\subsection{Fatty acid composition}

The fatty acid composition was carried out by an Agilent 6890-5973 gas chromatography-mass spectrometer (GC-MS; Agilent Technologies, CA, USA) analysis according to Li et al. (2013).

\subsection{Separation of TPC}

The separation of TPC from oil samples was performed using preparative flash chromatography (CHEETAH MP200, Bonna Agela Technology Company, China) according to the method of Cao et al. (2013) with some modifications. In order to effectively separate polar compounds, two preparation 
flash silica columns (silica gel: $20 \mathrm{~g}$; grain diameter: $40-60 \mu \mathrm{m}$ ) were used in series. The connected flash columns were flushed with the eluent A (petroleum ether:ethyl ether $=87: 13, \mathrm{v} / \mathrm{v}$ ) for $10 \mathrm{~min}$. Then the oil sample (1 g), dissolved in petroleum ether $(5 \mathrm{ml})$, was injected into the column by a $10-\mathrm{ml}$ syringe. After elution of the non-polar components with $250 \mathrm{ml}$ of eluent $\mathrm{A}$, the polar compounds were recovered with $500 \mathrm{ml}$ of eluent B (ethyl ether). The eluent velocity was set at $25 \mathrm{ml} / \mathrm{min}$. Then, the polar compounds dissolved in eluents B were subsequently submitted to rotary evaporation $\left(45^{\circ} \mathrm{C}\right)$ and vacuum drying $\left(40^{\circ} \mathrm{C}\right.$, $0.1 \mathrm{MPa})$. The obtained polar compounds were weighed to calculate their content based on the weight of each oil sample and were further analyzed.

The elution of non-polar compounds and polar compounds was completed within one hour, greatly shortening the time needed (approximately $7 \mathrm{~h}$ ) for silica gel column chromatography. The coefficient of variation of this separation method was less than $4 \%$ (Cao et al., 2013). The efficacy of separation was checked by thin layer chromatography according to the International Union of Pure and Applied Chemistry (IUPAC) Standard Method 2.507 (Paquot and Hautfenne, 1987).

\subsection{Distribution of TPC by the HPSEC}

The determination of distribution of TPC in oil samples involves the use of HPSEC for their separation, identification, and quantification. The chromatographic system consisted of Waters 2695 highperformance liquid chromatographic system, 2414 differential refractive index detector (RI), a 10- $\mu$ l injector loop, a Styragel gel chromatography guard column, and a series of two Styragel HR 0.5 volume exclusion gel columns $(7.8 \mathrm{~mm} \times 300 \mathrm{~mm}$, grain diameter $5 \mu \mathrm{m}$, aperture $10 \mathrm{~nm}$, Waters company).

Before injection, the obtained TPC from the previous procedure were dissolved in THF at the concentration of $10 \mathrm{mg} / \mathrm{ml}$, and filtered through a membrane $(0.22 \mu \mathrm{m})$. In line with the method of the previous report (Cao et al., 2013), the filtered solution was introduced through the injector loop $(10 \mu \mathrm{l})$. The temperature of both the columns and testing pool was set at $35{ }^{\circ} \mathrm{C}$. The THF was used as the mobile phase for HPSEC at a flow rate of $0.7 \mathrm{ml} / \mathrm{min}$. Peaks on the chromatograms were identified by SL-105 polystyrene standard relative molecular weight. TGO, TGD,
ox-TGM, DAG, and FFA of the oils were quantified with the peak area normalization method. All the determinations were carried out in triplicate.

\subsection{Statistical analysis}

Linear regression analysis of the data obtained from the separation of TPC of the oils was performed in Origin 8.0. Comparison between the means was made by applying one-way analysis of variance (ANOVA) using the statistical program SPSS Version 16.0 for Windows. A value of $P<0.05$ indicated statistical significance, using Duncan's multiple range tests.

\section{Results}

\subsection{Fatty acid composition}

The major fatty acids and their contents in CSO as well as EVOO, SBO, and PO are listed in Table 1. CSO mainly contained palmitic, stearic, oleic, and linoleic acids. The total content of unsaturated fatty acids (UFA) was $85.97 \%$, which was a little higher than that in EVOO and SBO. In particular, the content of oleic acid in CSO was up to $76.26 \%$, more than that in EVOO. However, palmitoleic and linolenic acids were not detected in CSO but found in EVOO. The highest linoleic acid was observed in SBO, whereas the highest content of palmitic acid and the highest saturated fatty acids (SFA) were observed in PO.

\subsection{Effect of heating time on the content of TPC}

A heating of $10 \mathrm{~h}$ caused a considerable augmentation in the weight percentages of TPC in CSO, as well as in the three other edible oils (Fig. 1). It was observed that the weight percentages of TPC from all the selected oils and the heating time fit linear equations. As predicted, the formation rate of the oils showed diversity due to their differences in fatty acid composition. However, despite the highest ratio (6.41) of UFA/SFA among these oils and higher TPC content before heating, CSO presented a much lower rate of increase of TPC content compared to that in EVOO and SBO. In addition, the content of TPC in all the oils was up to $24 \%$ or more after heating for $10 \mathrm{~h}$.

\subsection{Distribution of TPC}

The representative chromatogram of TPC obtained from $\mathrm{CSO}$ before and after heating is presented 
Table 1 Fatty acid composition of camellia seed oil (CSO), extra virgin olive oil (EVOO), soybean oil (SBO), and palm oil (PO) employed in the study

\begin{tabular}{|c|c|c|c|c|c|c|}
\hline Oil & $\begin{array}{c}\text { Palmitic acid } \\
(\%)\end{array}$ & $\begin{array}{c}\text { Palmitoleic } \\
\text { acid (\%) }\end{array}$ & $\begin{array}{c}\text { Stearic acid } \\
(\%)\end{array}$ & $\begin{array}{l}\text { Oleic acid } \\
(\%)\end{array}$ & $\begin{array}{c}\text { Linoleic acid } \\
(\%)\end{array}$ & $\begin{array}{c}\text { Linolenic } \\
\text { acid (\%) }\end{array}$ \\
\hline $\mathrm{CSO}$ & $10.52 \pm 0.03$ & - & $2.89 \pm 0.04$ & $76.26 \pm 0.05$ & $9.73 \pm 0.06$ & - \\
\hline EVOO & $14.77 \pm 0.05$ & $1.39 \pm 0.04$ & $5.32 \pm 0.06$ & $66.78 \pm 0.05$ & $8.67 \pm 0.08$ & $1.08 \pm 0.03$ \\
\hline SBO & $11.30 \pm 0.04$ & - & $4.66 \pm 0.07$ & $19.76 \pm 0.06$ & $53.68 \pm 0.04$ & $9.94 \pm 0.05$ \\
\hline $\mathrm{PO}$ & $34.83 \pm 0.05$ & $0.23 \pm 0.02$ & $5.13 \pm 0.06$ & $46.23 \pm 0.03$ & $11.67 \pm 0.07$ & $0.47 \pm 0.01$ \\
\hline Oil & $\begin{array}{c}\sum \mathrm{SFA}^{\mathrm{a}} \\
(\%)\end{array}$ & $\begin{array}{c}\mathrm{MUFA}^{\mathrm{b}} \\
(\%)\end{array}$ & $\begin{array}{c}\sum \text { PUFA }^{\mathrm{c}} \\
(\%)\end{array}$ & $\begin{array}{c}\sum \mathrm{UFA}^{\mathrm{d}} \\
(\%)\end{array}$ & $\sum \mathrm{UFA} / \sum \mathrm{SFA}^{\mathrm{e}}$ & \\
\hline $\mathrm{CSO}$ & $13.41 \pm 0.07$ & $76.26 \pm 0.05$ & $9.73 \pm 0.06$ & $85.99 \pm 0.03$ & $6.41 \pm 0.03$ & \\
\hline EVOO & $20.09 \pm 0.02$ & $68.16 \pm 0.08$ & $9.75 \pm 0.10$ & $77.91 \pm 0.04$ & $3.88 \pm 0.01$ & \\
\hline SBO & $15.96 \pm 0.06$ & $19.76 \pm 0.06$ & $63.63 \pm 0.03$ & $83.39 \pm 0.04$ & $5.22 \pm 0.02$ & \\
\hline PO & $39.96 \pm 0.01$ & $46.46 \pm 0.04$ & $12.13 \pm 0.08$ & $58.59 \pm 0.04$ & $1.47 \pm 0.01$ & \\
\hline
\end{tabular}

${ }^{\mathrm{a}}$ Sum of major saturated fatty acids; ${ }^{\mathrm{b}}$ Sum of major monounsaturated fatty acids; ${ }^{\mathrm{c}}$ Sum of major polyunsaturated fatty acids; ${ }^{\mathrm{d}}$ Sum of major unsaturated fatty acids; ${ }^{\mathrm{e}}$ Total unsaturated fatty acids to total saturated fatty acids ratio

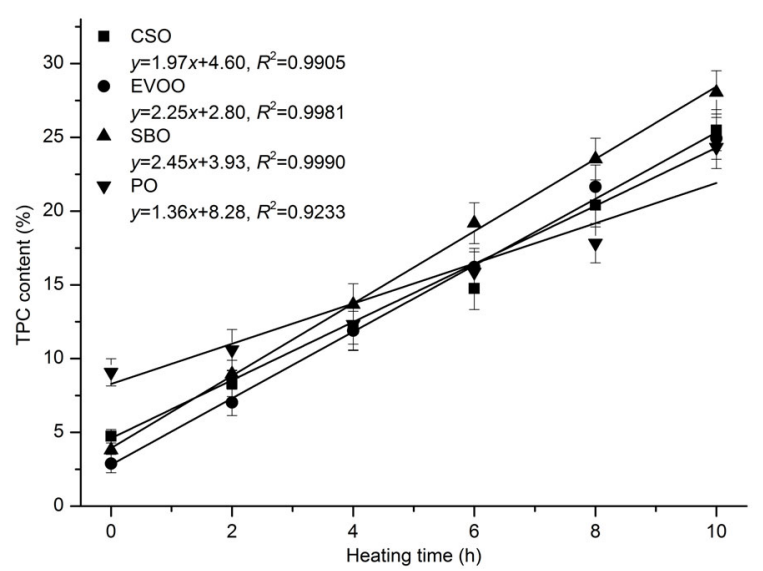

Fig. 1 Effect of heating time on TPC content in camellia seed oil (CSO), extra virgin olive oil (EVOO), soybean oil (SBO), and palm oil (PO) during heating

Error bars indicate standard deviations for three replicates

in Fig. 2. Five main peaks, eluting in inverse order of molecular weight, were resolved: TGO, TGD, oxTGM, DAG, and FFA.

As is clearly seen from Fig. 2, heating caused a significant shift of the HPSEC of the polar fractions isolated from CSO after heating for $10 \mathrm{~h}$. Quantitative results of the relative ( $\%$ of polar content) and absolute $(\%(\mathrm{w} / \mathrm{w})$ on oil) contents for different groups of alteration products throughout the heating process are given in Tables 2 and 3, respectively.

Table 2 shows that the relative contents of TGO, TGD, ox-TGM, DAG, and FFA in CSO before heating were $5.22 \%, 17.62 \%, 20.32 \%, 46.58 \%$, and $3.47 \%$, respectively. Heating for $10 \mathrm{~h}$ resulted in a significant $(P<0.05)$ increase of the relative contents

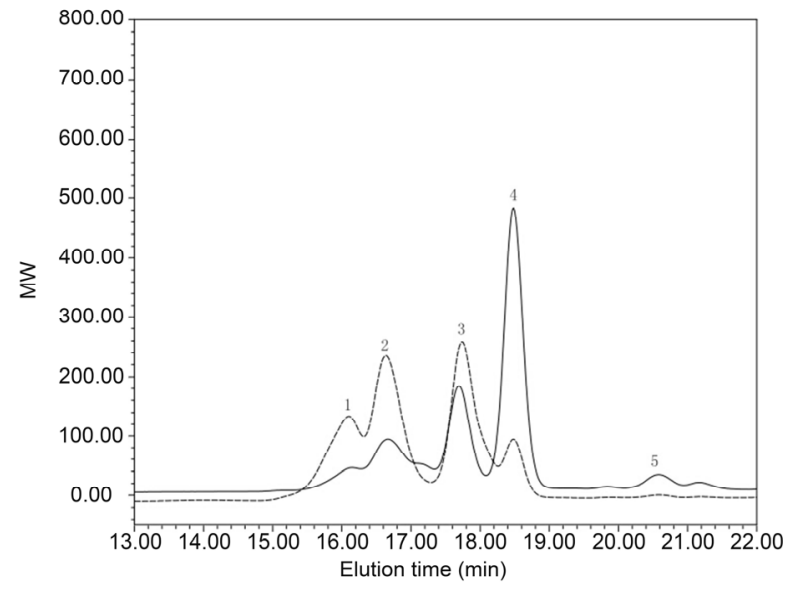

Fig. 2 HPSEC analysis of polar compounds in camellia seed oil (CSO) before (solid line) and after (dashed line) heating for $10 \mathrm{~h}$

Peaks: 1, oxidized triacylglycerol oligomers (TGO); 2, oxidized triacylglycerol dimers (TGD); 3, oxidized triacylglycerol monomers (ox-TGM); 4, diacylglycerols (DAG); 5, free fatty acids (FFA). MW: molecular weight

of TGO, TGD, and ox-TGM in CSO, respectively up to $20.93 \%, 34.11 \%$, and $33.89 \%$, indicating the extent of oxidative degradation in CSO was aggravated by heating. This result also suggested that the formation rate of TGO was the fastest, followed by TGD then ox-TGM during the heating of CSO. Moreover, their absolute contents in CSO were also increased in this order (Table 3). It is noteworthy that the relative content of ox-TGM in CSO reached a steady state after heating for $6 \mathrm{~h}$. In addition, heating also resulted in a significant $(P<0.05)$ decrease of the relative contents of DAG and FFA in CSO (Table 2). 
Table 2 Distribution of polar components in TPC of camellia seed oil (CSO) during heating

\begin{tabular}{cccccc}
\hline \multirow{2}{*}{$\begin{array}{c}\text { Heating time } \\
(\mathrm{h})\end{array}$} & \multicolumn{5}{c}{ Relative content $(\%)^{*}$} \\
\cline { 2 - 6 } & \multicolumn{1}{c}{ TGO } & TGD & ox-TGM & DAG & FFA \\
\hline 0 & $5.22 \pm 0.24^{\mathrm{f}}$ & $17.62 \pm 0.51^{\mathrm{f}}$ & $20.35 \pm 0.33^{\mathrm{d}}$ & $46.58 \pm 1.04^{\mathrm{a}}$ & $3.47 \pm 0.35^{\mathrm{a}}$ \\
2 & $8.64 \pm 0.33^{\mathrm{e}}$ & $22.03 \pm 0.59^{\mathrm{e}}$ & $24.45 \pm 0.36^{\mathrm{c}}$ & $36.42 \pm 0.91^{\mathrm{b}}$ & $2.83 \pm 0.26^{\mathrm{b}}$ \\
4 & $11.81 \pm 0.35^{\mathrm{d}}$ & $25.63 \pm 0.69^{\mathrm{d}}$ & $27.98 \pm 0.49^{\mathrm{b}}$ & $28.61 \pm 0.81^{\mathrm{c}}$ & $2.26 \pm 0.25^{\mathrm{c}}$ \\
6 & $15.77 \pm 0.26^{\mathrm{c}}$ & $31.21 \pm 0.58^{\mathrm{c}}$ & $33.41 \pm 0.51^{\mathrm{a}}$ & $15.58 \pm 0.77^{\mathrm{d}}$ & $1.68 \pm 0.22^{\mathrm{d}}$ \\
8 & $18.22 \pm 0.29^{\mathrm{b}}$ & $32.71 \pm 0.64^{\mathrm{b}}$ & $33.65 \pm 0.48^{\mathrm{a}}$ & $12.46 \pm 0.67^{\mathrm{e}}$ & $1.13 \pm 0.19^{\mathrm{e}}$ \\
10 & $20.93 \pm 0.27^{\mathrm{a}}$ & $34.11 \pm 0.57^{\mathrm{a}}$ & $33.89 \pm 0.44^{\mathrm{a}}$ & $9.07 \pm 0.52^{\mathrm{f}}$ & $0.62 \pm 0.12^{\mathrm{f}}$ \\
\hline
\end{tabular}

TPC: total polar compounds; TGO: oxidized triacylglycerol oligomers; TGD: oxidized triacylglycerol dimmers; ox-TGM: oxidized triacylglycerol monomers; DAG: diacylglycerols; FFA: free fatty acids. " All data are relative contents in TPC (w/w), and are expressed as mean \pm standard deviation of triplicate determinations; values in the same column bearing different letters are significantly different $(P<0.05)$

Table 3 Distribution of polar components in camellia seed oil during heating

\begin{tabular}{cccccc}
\hline \multirow{2}{*}{$\begin{array}{c}\text { Heating time } \\
(\mathrm{h})\end{array}$} & \multicolumn{5}{c}{ Absolute content $(\%)^{*}$} \\
\cline { 2 - 5 } & TGO & TGD & ox-TGM & DAG & FFA \\
\hline 0 & $0.25 \pm 0.03^{\mathrm{f}}$ & $0.83 \pm 0.06^{\mathrm{f}}$ & $0.96 \pm 0.08^{\mathrm{f}}$ & $2.20 \pm 0.16^{\mathrm{c}}$ & $0.17 \pm 0.03^{\mathrm{b}}$ \\
2 & $0.72 \pm 0.10^{\mathrm{e}}$ & $1.83 \pm 0.14^{\mathrm{e}}$ & $2.03 \pm 0.18^{\mathrm{e}}$ & $3.02 \pm 0.24^{\mathrm{ab}}$ & $0.24 \pm 0.05^{\mathrm{ab}}$ \\
4 & $1.42 \pm 0.13^{\mathrm{d}}$ & $3.07 \pm 0.29^{\mathrm{d}}$ & $3.36 \pm 0.35^{\mathrm{d}}$ & $3.43 \pm 0.32^{\mathrm{a}}$ & $0.27 \pm 0.06^{\mathrm{a}}$ \\
6 & $2.32 \pm 0.19^{\mathrm{c}}$ & $4.60 \pm 0.36^{\mathrm{c}}$ & $4.93 \pm 0.40^{\mathrm{c}}$ & $2.31 \pm 0.34^{\mathrm{c}}$ & $0.25 \pm 0.06^{\mathrm{ab}}$ \\
8 & $3.72 \pm 0.21^{\mathrm{b}}$ & $6.67 \pm 0.35^{\mathrm{b}}$ & $6.86 \pm 0.40^{\mathrm{b}}$ & $2.55 \pm 0.32^{\mathrm{bc}}$ & $0.23 \pm 0.06^{\mathrm{ab}}$ \\
10 & $5.33 \pm 0.22^{\mathrm{a}}$ & $8.69 \pm 0.33^{\mathrm{a}}$ & $8.63 \pm 0.36^{\mathrm{a}}$ & $2.32 \pm 0.26^{\mathrm{c}}$ & $0.16 \pm 0.04^{\mathrm{b}}$ \\
\hline
\end{tabular}

${ }^{*}$ All data are absolute contents in CSO (w/w), and are expressed as mean \pm standard deviation of triplicate determinations; values in the same column bearing different letters are significantly different $(P<0.05)$. For abbreviation see Table 2

In terms of the absolute contents of these polar components, TGO, TGD, and ox-TGM increased significantly $(P<0.05)$ with prolonged heating, while small changes were observed in DAG and FFA (Table 3), suggesting that a high extent of oxidative degradation and a low level of hydrolytic degradation of $\mathrm{CSO}$ occurred during heating.

Fig. 3 describes the change in the relative contents of oxidative products and hydrolytic products in EVOO, SBO, and PO, as well as comparison with that in CSO. Interestingly, for the relative contents of ox-TGM, a decreasing trend was observed only in $\mathrm{SBO}$, whereas a continuously increasing throughout approximately $6 \mathrm{~h}$, followed by a tendency to reach a near-steady state in later successive heating, was observed both in CSO and EVOO. Moreover, it was also observed that ox-TGM and TGD in CSO presented a slower formation rate than that in EVOO. However, the formation rate of TGO was a little higher in CSO than in EVOO.

The evolution of the absolute contents of these polar components in the oils was also illustrated and compared, as shown in Fig. 4. It appears that the rates of increase of ox-TGM content and TGD content were much slower in CSO than in EVOO during heating, although higher values of ox-TGM content and TGD content were found in the former before heating. Only small differences were found in TGO content when considering the wide variation in the ratio of UFA/SFA of the oils assayed, as shown in Table 1.

\section{Discussion}

As a new food resource, CSO is economically important for human consumption and has been widely used for making cooking oil and medicines (Su et al., 2014). In application, heating is inevitable. During heating, the oil is prone to undergo lipid oxidation, resulting in the degradation and alteration of triacylglycerol and the formation of new compounds with polarity (Ng et al., 2014). Under the same conditions, the formation rate of TPC in the oil is mainly dependent on its fatty acids composition and the content of antioxidant. However, the natural antioxidant presented in the oil is lost rapidly during heating 

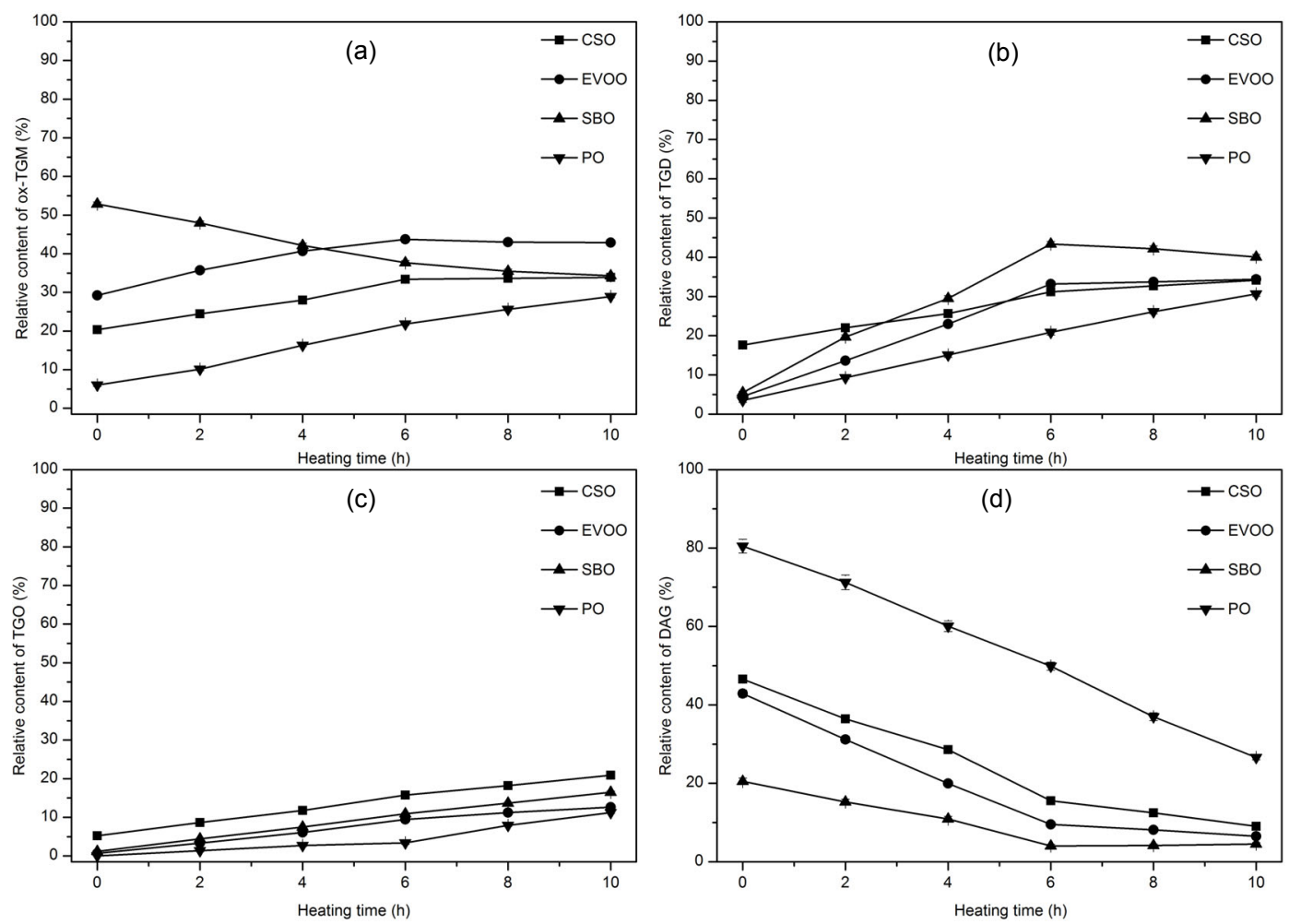

Fig. 3 Changes in the relative contents of ox-TGM (a), TGD (b), TGO (c), and DAG (d) in camellia seed oil (CSO), extra virgin olive oil (EVOO), soybean oil (SBO), and palm oil (PO) during heating at $180{ }^{\circ} \mathrm{C}$ for $10 \mathrm{~h}$ Error bars indicate standard deviations for three replicates
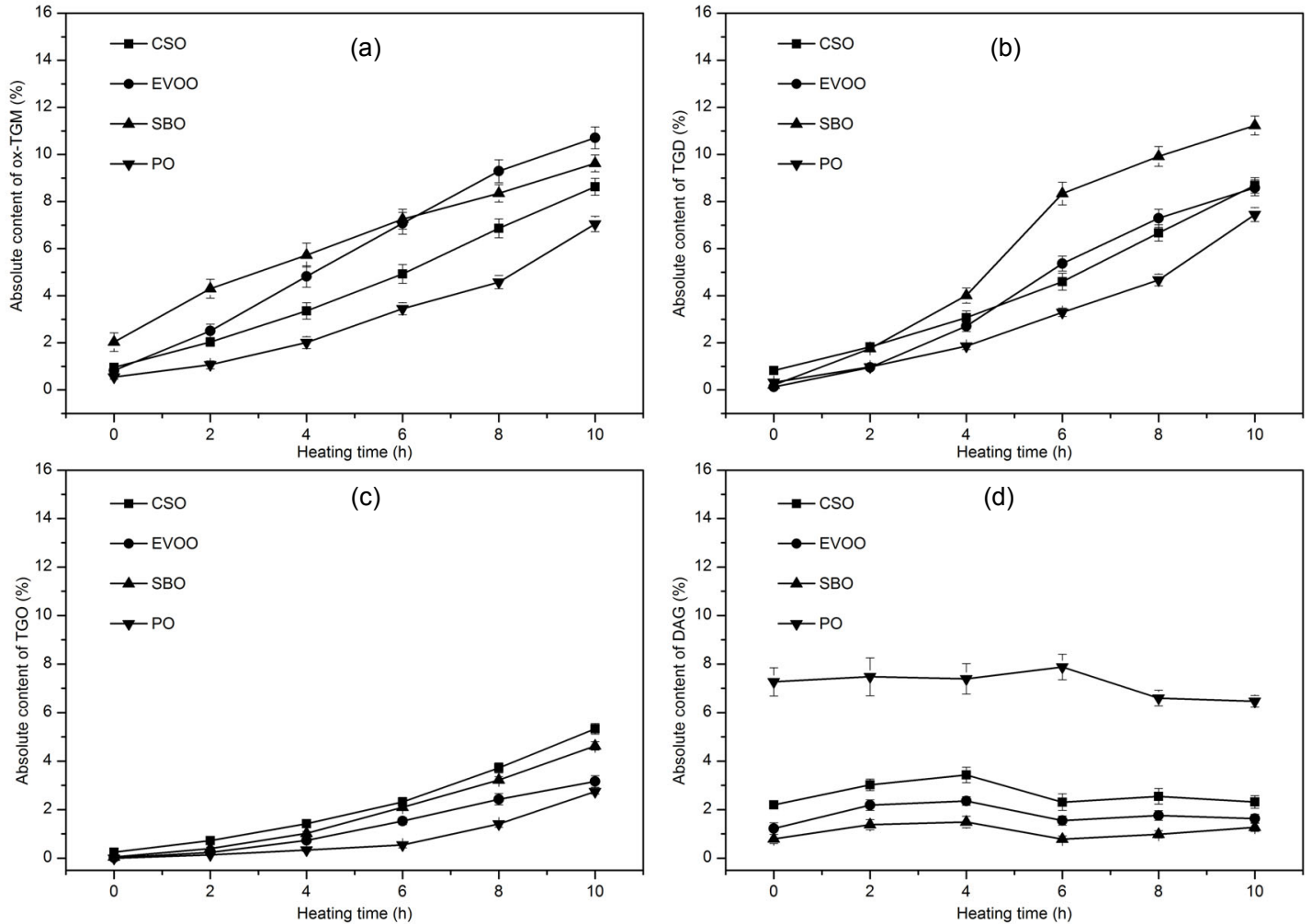

Fig. 4 Changes in the absolute contents of ox-TGM (a), TGD (b), TGO (c), and DAG (d) in camellia seed oil (CSO), extra virgin olive oil (EVOO), soybean oil (SBO), and palm oil (PO) during heating at $180{ }^{\circ} \mathrm{C}$ for $10 \mathrm{~h}$ Error bars indicate standard deviations for three replicates 
and its loss was independent of the degree of oil unsaturation (Barrera-Arellano et al., 2002). In our study, the content of TPC in oils was intensified progressively with processing time (Fig. 1). Despite this, CSO exhibited a higher stability due to the presence of high amounts of oleic acid. The distinct formation rate of TPC was found in the selected oils, demonstrating that the fatty acid composition has an apparent impact on the thermal oxidation, hydrolysis, and polymerization of oils. This result is inconsistent with the previous report, in which Marmesat et al. (2012) stated that the levels of all the new compounds formed during thermoxidation, i.e., polymers, polar compounds, and polar fatty acids, strongly depended on the degree of oil unsaturation.

Research has shown that TPC isolated from thermally oxidized oils are toxic to laboratory animals (Pantzaris, 1998). Therefore, it has been recommended that the thermally oxidized oils containing more than $24 \%-27 \%$ of TPC content should be discarded (Caldwell et al., 2011; Correia et al., 2015). Assuming that the limit of acceptance for the TPC content is $25 \%$, the time required to reach this limit was considered as a measure of oil's useful lifetime (Marmesat et al., 2012). From the calculated measures and the linear equations displayed in Fig. 1, CSO showed a higher thermal stability $(10.25 \mathrm{~h})$ than that of EVOO (9.82 h) or SBO (8.61 h). From these results, it can be seen that $\mathrm{CSO}$ was more resistant to oxidation degradation than EVOO and SBO. In the case of PO, due to its high content of SFA, it was considered to be the most stabile $(11.90 \mathrm{~h})$ cooking oil Although the suitability of PO for heating and frying has been widely demonstrated in many studies, the PO was unfavorable in view of health aspects (Matthäus, 2007). Considering the requirement for dietary fatty acid and the formation rate of TPC, CSO exhibited a better lifecycle and is more suitable than EVOO and SBO for use as cooking oil.

Analysis of the TPC enables an overall evaluation of both hydrolytic and oxidative degradation of edible oils and fats (Caponio et al., 2007). Further application of HPSEC to the isolated polar compounds allowed differentiation of the main groups of compounds present and establishment of the relative influence of three degradation pathways predominant in heating: hydrolysis, polymerization, and oxidation
(Romero et al., 1995). Significant peak separation enabled determination of the amounts of TGD, TGO, ox-TGM, DAG, and FFA (Fig. 2). Oxidized triglyceride polymers (TGPs), including TGD and TGO, are a reliable index of secondary oxidative degradation of the oil, because they are stable and not influenced by processing conditions. On the contrary, ox-TGM are triglycerides having higher polarity than unaltered triglycerides, and mainly consist of triglyceride hydroperoxides as well as triglycerides in which the hydroperoxydic functional group has been transformed in the alcoholic or carbonyl group (Gomes et al., 2012). The ox-TGM can give information about the primary oxidation level of oil. Finally, DAG and FFA constitute reliable parameters for a proper evaluation of the real level of hydrolytic degradation of refined oils (Caponio et al., 2011).

Note that differences in distribution of each polar component can be related to differences in the nutritional value of oils. DAG and FFA are the common compounds originating during lipid metabolism but TGP and ox-TGM contain altered acyl groups which would weaken the nutritional properties (Romero et al., 1995). Therefore, it is necessary to determine the contribution of each of them to the total alteration. In this study comparing the distribution of each polar component before and after heating, a significant change was found, indicating that heating induced the breakage and reform of triglycerides. As shown in Tables 2 and 3, the increased percentage of TGO content based on the weight of TPC from CSO was considerably higher than that of TGD. This is in accordance with a previous report, suggesting a higher tendency for formation of TGO than of TGD, although TGD was the principal component of TPC throughout the heating process (Farhoosh and Tavassoli-Kafrani, 2010). Moreover, in contrast to other oils, the increased percentage of TGO based on the weight of TPC in CSO was the lowest after heating for $10 \mathrm{~h}$ (Fig. 3). This might be attributable to the low content of linoleic acid, which can cause polymerization (Su et al., 2014). These results demonstrate that CSO has a higher ability to resist polymer formation than the other oils.

In terms of thermally oxidized products, i.e., ox-TGM, its amount based on the weight of TPC in CSO and EVOO also increased continuously 
throughout approximately $6 \mathrm{~h}$, followed by a tendency to reach a near-steady state in later successive heating (Fig. 3). This might be due to ox-TGM not only being present in primary oxidation compounds but also participating in the formation of polymerization compounds after prolonged heating (Martín-Polvillo et al., 2004). Because ox-TGM were not final products of oxidation (Gomes et al., 2012), further degradation can be induced by processing. However, in $\mathrm{SBO}$, it was consistently decreasing, and in $\mathrm{PO}$, it was significantly $(P<0.05)$ increasing throughout the successive heating. This difference could be associated with the oxidation stage, which the oil undergoes. Given its pro-oxidant activity (Gomes et al., 2011) and cytotoxicity (Wenci, 2014), the higher contribution of ox-TGM with regard to the other polar components altered by heating also should be noted.

As reported by Arroyo et al. (1992), a decreasing tendency and a fluctuant tendency for the relative and absolute contents of DAG and FFA, respectively, were observed. This is in agreement with the present study. Moreover, low amounts of FFA added to purified olive oil caused a further increase in the content of ox-TGM and TGP, suggesting a pro-oxidant activity of FFA (Paradiso et al., 2010). Likewise, DAG was also proved to have a pro-oxidant effect on SBO. Thus, there should be strict control of their content in the oil (Mistry and Min, 1988).

With regard to the safe limits of polar compounds, it was observed that the content of polar compounds of all oils was higher than $24 \%$ after heating for $10 \mathrm{~h}$. Due to the toxicological characteristics of TGP (including TGD and TGO), some researchers reported that oils containing 10\% TGP should be discarded (Farhoosh and Tavassoli-Kafrani, 2010). Other researchers reported that the recommended and widely accepted limits are $12 \%$ for TGP (Weisshaar, 2014). Further harmonization of regulations on the quality control of oxidized oil is desirable. In this study, it was observed that the content of TGP was $10.39 \%$ for CSO after heating for $8 \mathrm{~h}$, whereas that of TPC was $20.41 \%$, i.e., less than $24 \%$. This fact further confirmed the more severe or restrictive requirement of oil quality for TGP content. Thus, it is essential to take account of both the contents of TPC and TGP as the standard when judging the useful lifetime of the oil.

\section{Conclusions}

In summary, this study provides useful information on the formation and distribution of TPC in CSO. CSO had a much lower formation rate of TPC compared to EVOO and SBO. Further analysis of TPC via HPSEC showed that the amount of oxidative products, ox-TGM, TGD, and TGO, increased significantly $(P<0.05)$ in CSO with heating time. The results obtained can justify the important value of CSO as an attractive and healthy cooking oil.

\section{Compliance with ethics guidelines}

Hong-xia FENG, Rokayya SAM, Lian-zhou JIANG, Yang LI, and Wen-ming CAO declare that they have no conflict of interest.

This article does not contain any studies with human or animal subjects performed by any of the authors.

\section{References}

Arroyo, R., Cuesta, C., Garrido-Polonio, C., et al., 1992. Highperformance size-exclusion chromatographic studies on polar components formed in sunflower oil used for frying. J. Am. Oil Chem. Soc., 69(6):557-563. http://dx.doi.org/10.1007/BF02636108

Barrera-Arellano, D., Ruiz-Méndez, V., Velasco, J., et al., 2002. Loss of tocopherols and formation of degradation compounds at frying temperatures in oils differing in degree of unsaturation and natural antioxidant content. $J$. Sci. Food Agric., 82(14):1696-1702. http://dx.doi.org/10.1002/jsfa.1245

Caldwell, J.D., Cooke, B.S., Greer, M.K., 2011. High performance liquid chromatography-size exclusion chromatography for rapid analysis of total polar compounds in used frying oils. J. Am. Oil Chem. Soc., 88(11):1669-1674. http://dx.doi.org/10.1007/s11746-011-1845-5

Cao, W.M., Zhang, K.Y., Xue, B., et al., 2013. Determination of oxidized triacylglycerol polymers by preparative flash chromatography and high-performance size-exclusion chromatography. Asian J. Chem., 25(16):9189-9194. http://dx.doi.org/10.14233/ajchem.2013.15139

Caponio, F., Gomes, T., Pasqualone, A., et al., 2007. Use of the high performance size exclusion chromatography analysis for the measurement of the degree of hydrolytic and oxidative degradation of the lipid fraction of biscuits. Food Chem., 102(1):232-236. http://dx.doi.org/10.1016/j.foodchem.2006.04.047

Caponio, F., Summo, C., Bilancia, M.T., et al., 2011. High performance size-exclusion chromatography analysis of polar compounds applied to refined, mild deodorized, extra virgin olive oils and their blends: an approach to their differentiation, LWT-Food Sci. Technol., 44(8): 1726-1730. http://dx.doi.org/10.1016/j.lwt.2011.03.025 
Correia, A.C., Dubreucq, E., Ferreira-Dias, S., et al., 2015 Rapid quantification of polar compounds in thermooxidized oils by hptlc-densitometry. Eur. J. Lipid Sci. Technol., 117(3):311-319.

http://dx.doi.org/10.1002/ejlt.201400230

Dobarganes, M., Pérez-Camino, M., Márquez-Ruíz, G., 1988. High performance size exclusion chromatography of polar compounds in heated and non-heated fats. Lipid/ Fett, 90(8):308-311. http://dx.doi.org/10.1002/lipi.19880900805

Farhoosh, R., Tavassoli-Kafrani, M.H., 2010. Polar compounds distribution of sunflower oil as affected by unsaponifiable matters of bene hull oil (BHO) and tertiary-butylhydroquinone (TBHQ) during deep-frying. Food Chem., 122(1):381-385. http://dx.doi.org/10.1016/j.foodchem.2010.02.066

Gomes, T., Delcuratolo, D., Paradiso, V.M., et al., 2011. Pro-oxidant activity of oxidized triacylglycerols in olive oil and comparison with pro-oxidant action of polar triacylglycerol oligopolymers. LWT-Food Sci. Technol., 44(4):1236-1239.

http://dx.doi.org/10.1016/j.lwt.2010.12.004

Gomes, T., Caponio, F., Durante, V., et al., 2012. The amounts of oxidized and oligopolymeric triacylglycerols in refined olive oil as a function of crude oil oxidative level. LWT-Food Sci. Technol., 45(2):186-190. http://dx.doi.org/10.1016/j.lwt.2011.07.008

Guillén, M.D., Uriarte, P.S., 2013. Relationships between the evolution of the percentage in weight of polar compounds and that of the molar percentage of acyl groups of edible oils submitted to frying temperature. Food Chem., 138(2-3):1351-1354. http://dx.doi.org/10.1016/j.foodchem.2012.10.108

Hai, Z., Wang, J., 2006. Detection of adulteration in camellia seed oil and sesame oil using an electronic nose. Eur. J. Lipid Sci. Technol., 108(2):116-124. http://dx.doi.org/10.1002/ejlt.200501224

Li, Y., Zhang, Y., Wang, M., et al., 2013. Simplex-centroid mixture design applied to the aqueous enzymatic extraction of fatty acid-balanced oil from mixed seeds. $J$. Am. Oil Chem. Soc., 90(3):349-357. http://dx.doi.org/10.1007/s11746-012-2180-1

Lim, J., Kim, Y.S., Kim, S.H., et al., 2013. Triglyceride enhances susceptibility to TNF- $\alpha$-induced cell death in THP-1 cells. Genes Genom., 36(1):87-93. http://dx.doi.org/10.1007/s13258-013-0144-y

Marmesat, S., Morales, A., Velasco, J., et al., 2012. Influence of fatty acid composition on chemical changes in blends of sunflower oils during thermoxidation and frying. Food Chem., 135(4):2333-2339. http://dx.doi.org/10.1016/j.foodchem.2012.06.128

Martín-Polvillo, M., Márquez-Ruiz, G., Dobarganes, M.C., 2004. Oxidative stability of sunflower oils differing in unsaturation degree during long-term storage at room temperature. J. Am. Oil Chem. Soc., 81(6):577-583. http://dx.doi.org/10.1007/s11746-006-0944-1
Matthäus, B., 2007. Use of palm oil for frying in comparison with other high-stability oils. Eur. J. Lipid Sci. Technol., 109(4):400-409. http://dx.doi.org/10.1002/ejlt.200600294

Mistry, B.S., Min, D.B., 1988. Prooxidant effects of monoglycerides and diglycerides in soybean oil. J. Food Sci., 53(6):1896-1897. http://dx.doi.org/10.1111/j.1365-2621.1988.tb07869.x

$\mathrm{Na}, \mathrm{Z} ., 2008$. A review on the refinement of the camellia oleifera seed oil and its application in cosmetics. Guangdong Forestry Sci. Technol., 24(4):87-91 (in Chinese).

Ng, C.Y., Leong, X.F., Adam, S.M., et al., 2014. Reprint of "heated vegetable oils and cardiovascular disease risk factors". Vasc. Pharmacol., 62(1):38-46. http://dx.doi.org/10.1016/j.vph.2014.05.003

Pantzaris, T., 1998. Comparison of monounsaturated and polyunsaturated oils in continuous frying. Grasas Aceites, 49(3-4):319-325. http://dx.doi.org/10.3989/gya.1998.v49.i3-4.733

Paquot, C., Hautfenne, A., 1987. IUPAC: Standard Methods for the Analysis of Oils, Fats, and Derivatives. Blackwell Scientific Publications, Oxford.

Paradiso, V.M., Gomes, T., Nasti, R., et al., 2010. Effects of free fatty acids on the oxidative processes in purified olive oil. Food Res. Int., 43(5):1389-1394. http://dx.doi.org/10.1016/j.foodres.2010.04.015

Romero, A., Cuesta, C., Sánchez-Muniz, F., 1995. Quantitation and distribution of polar compounds in an extra virgin olive oil used in fryings with turnover of fresh oil. Lipid/Fett, 97(11):403-407. http://dx.doi.org/10.1002/lipi.2700971102

Salinero, C., Feas, X., Mansilla, J.P., et al., 2012. ${ }^{1} \mathrm{H}$-nuclear magnetic resonance analysis of the triacylglyceride composition of cold-pressed oil from Camellia japonica. Molecules, 17(6):6716-6727. http://dx.doi.org/10.3390/molecules 17066716

Su, M.H., Shih, M.C., Lin, K.H., 2014. Chemical composition of seed oils in native taiwanese camellia species. Food Chem., 156(0):369-373. http://dx.doi.org/10.1016/j.foodchem.2014.02.016

Wang, X.Q., Liang, X.Q., Zhao, J., et al., 2014. Cultivar characterization of tea seed oils by their active components and antioxidant capacity. J. Am. Oil Chem. Soc., 91(4):629-639. http://dx.doi.org/10.1007/s11746-013-2397-7

Wang, Y.F., Wang, J., Wu, J., et al., 2014. In vitro antioxidant activity and potential inhibitory action against $\alpha$ glucosidase of polysaccharides from fruit peel of tea (Camellia sinensis L.). J. Zhejiang Univ.-Sci. B (Biomed. \& Biotechnol.), 15(2):173-180. http://dx.doi.org/10.1631/jzus.B1300186

Weisshaar, R., 2014. Quality control of used deep-frying oils. Eur. J. Lipid Sci. Technol., 116(6):716-722. http://dx.doi.org/10.1002/ejlt.201300269

Wenci, C., 2014. Analysis and Cytotoxicity Evaluation of Polar Components in Frying Oil. MS Thesis, Jiangnan University, Wuxi, China (in Chinese). 
Zeb, A., 2012. Triacylglycerols composition, oxidation and oxidation compounds in camellia oil using liquid chromatography-mass spectrometry. Chem. Phys. Lipids, 165(5):608-614.

http://dx.doi.org/10.1016/j.chemphyslip.2012.03.004

\section{中文概要}

题 目: 采用高效体积排阻色谱技术研究油茶䊏油在加热 过程中极性化合物的形成及其组分分布

目 的：测定加热过程中油茶籽油中极性化合物及其组分 的变化, 同时与其它常用油脂进行对比, 评估油 茶籽油作为煎炸用油的优势。

创新点：首次在油茶籽油中采用制备型硅胶柱层析一高效 体积排阻色谱技术，监测了极性化合物总量及其 组分分布在加热过程中的变化规律, 预估油茶籽 油的使用寿命, 为煎炸用油的选择提供科学理论 依据。
方 法: 取等量市售油茶籽油、橄榄油、大豆油和棕㭣油, 在 $180^{\circ} \mathrm{C}$ 分别加热 2、4、6、8 和 10 小时并收集 样品。实验结束后, 首先利用制备型硅胶柱层析 分离测定总极性化合物含量的变化, 并采用高效 体积排阻色谱技术对分离得到的极性化合物组 分进行定量分析。

结 论: 油茶籽油在加热过程中所形成的极性化合物总量 （TPC）呈线性增加趋势, 其形成速率显著低于 橄榄油和大豆油（图 1）。随着加热时间的延长, 油茶籽油中的氧化甘油三酯 (ox-TGM) 、氧化 甘油三酯二聚物 (TGD) 和氧化甘油三酯多聚物 (TGO) 的含量显著增加 $(P<0.05)$ 。此外, ox-TGM和 TGD 在油茶籽油中的形成速率明显低 于其在橄榄油和大豆油中的形成速率, 然而这三 种油脂之间的 TGO 含量的变化不存在显著差异 (图 4)。综上所述, 油茶籽油可作为一种具有 开发前景和健康食用价值的煎炸用油。

关键词: 油茶籽油; 极性化合物; 高效体积排阻色谱技术; 氧化 